\title{
Cervical Supine Side-Bending versus Cervical Supine Traction Radiographs: Which Is Better in Predicting Proximal Thoracic Flexibility for Lenke 1 and 2 Adolescent Idiopathic Scoliosis?
}

\author{
Chee Kidd Chiu ${ }^{1}$, Elrofai Suliman Bashir ${ }^{2}$, Chris Yin Wei Chan ${ }^{1}$, Mun Keong Kwan ${ }^{1}$ \\ ${ }^{1}$ Department of Orthopaedic Surgery, National Orthopaedic Centre of Excellence for Research and Learning, Faculty of Medicine, University of Malaya, \\ Kuala Lumpur, Malaysia \\ ${ }^{2}$ Faculty of Medicine, Elneelain University, Khartoum, Sudan
}

Study Design: Prospective cohort study.

Purpose: This study compared cervical supine side-bending (CSSB) and cervical supine traction (CST) radiographs to assess the flexibility and predict the correctability of the proximal thoracic (PT) curve for patients with adolescent idiopathic scoliosis (AIS) classified as Lenke 1 and 2.

Overview of Literature: Knowledge of the flexibility of the PT curve is crucial in the management of patients with AIS. There are no reports comparing CSSB and CST radiographs to assess this parameter.

Methods: Thirty patients with Lenke 1 and 2 AIS scheduled for posterior spinal fusion surgery were recruited. A standing whole spine radiography and physician-supervised CSSB and CST radiographies were performed. Patient demographic and radiological parameters were recorded, including age, gender, weight, height, body mass index, PT angle, main thoracic angle, CSSB PT angle, CST PT angle, and postoperative PT angle. From the data collected, the curve flexibility and curve correction index were calculated and compared.

Results: CSSB had a significantly $(p<0.05)$ smaller PT angle $\left(16.6^{\circ} \pm 10.4^{\circ}\right)$ in comparison to CST $\left(23.7^{\circ} \pm 10.7^{\circ}\right)$. CSSB had significantly $(p<0.05)$ greater flexibility $(44.2 \% \pm 19.7 \%)$ in comparison to CST $(19.5 \% \pm 18.1 \%)$. The CSSB correction index $(1.2 \pm 0.9)$ was significantly closer to 1 in comparison to the CST correction index (4.4 \pm 5.3$)$. There was no difference $(p=0.72)$ between the CSSB PT angle $\left(16.6^{\circ} \pm 10.4^{\circ}\right)$ and the postoperative PT angle $\left(16.1^{\circ} \pm 7.5^{\circ}\right)$. However, the CST PT angle $\left(23.7^{\circ} \pm 10.7^{\circ}\right)$ was significantly $(p<0.05)$ larger than the postoperative PT angle $\left(16.1^{\circ} \pm 7.5^{\circ}\right)$.

Conclusions: CSSB radiographs were better for demonstrating PT flexibility and more accurately predicted correctability in comparison to the CST radiographs.

Keywords: Neck; Scoliosis; Adolescent; Spine; Radiography; Thoracic vertebrae

Received Oct 26, 2017; Revised Nov 20, 2017; Accepted Dec 17, 2017

Corresponding author: Chris Yin Wei Chan

Department of Orthopaedic Surgery, National Orthopaedic Centre of Excellence for Research and Learning, Faculty of Medicine, University of Malaya, 50603 Kuala Lumpur, Malaysia

Tel: +60-128830301, Fax: +60-379494642, E-mail: cheekidd@um.edu.my 


\section{Introduction}

The surgical correction of adolescent idiopathic scoliosis (AIS) aims to fuse the structural curves with the least number of fusion levels possible while maintaining a balanced body. However, it had been recognized that in some cases, the unfused compensatory curves above or below the main structural curve are unable to compensate after surgical correction, and "letting go" of the initial curve correction was required to achieve a balanced shoulder and pelvis [1]. The flexibility of the proximal thoracic (PT) segments plays an important role in determining whether the surgical correction of the main thoracic (MT) curve will lead to neck and shoulder imbalance [2-4]. An imbalanced neck or shoulder after surgery may result in cosmetic dissatisfaction among patients [5]. As the selection of fusion levels determines the alignment and compensation of the unfused segments, the flexibility of the PT segment may govern the selection of the upper instrumented vertebra during corrective surgery.

Although some authors have stressed the importance of recognizing the rigidity and structurality of the PT curve prior to surgical correction [6], the results of these studies are based on the evaluation of conventional whole spine and supine side-bending radiographs. In the literature, several methods of radiographically assessing the flexibility of the main scoliotic curve using supine bending films, axial suspension films, push-prone films, push-traction films, fulcrum bending films, and traction films have been reported; however, these studies have not investigated PT flexibility [7-14].

Kirk et al. [15] investigated the flexibility of the PT curve by comparing the supine traction radiograph with the conventional supine side-bending radiograph. They found that greater flexibility of the curve was visualized with the supine traction radiograph in comparison to the supine side-bending radiograph. Cervical supine sidebending (CSSB) radiographs are films that combine supervised bending of the cervical spine and bending of the whole spine in the supine position [16]. It is postulated that the CSSB radiographs provide a better assessment of the flexibility of the PT curve in comparison to the conventional supine side-bending radiographs or even the supine traction radiographs. Therefore, the present study analyzed and compared the ability of CSSB and cervical supine traction (CST) radiographs to determine the flexibility and correctability of the PT curve in patients with Lenke 1 and 2 AIS.

\section{Materials and Methods}

This prospective clinical-radiological study was conducted between December 2015 and June 2016. Ethical approval from University Malaya Medical Centre review board was obtained (Ethical approval no., MECID No. 20159-1630). Inclusion criteria for this study were patients diagnosed with AIS with Lenke 1 or 2 curve who were candidates for posterior spinal fusion. Patients with nonidiopathic scoliosis and revision cases were excluded.

All patients underwent routine preoperative radiog-
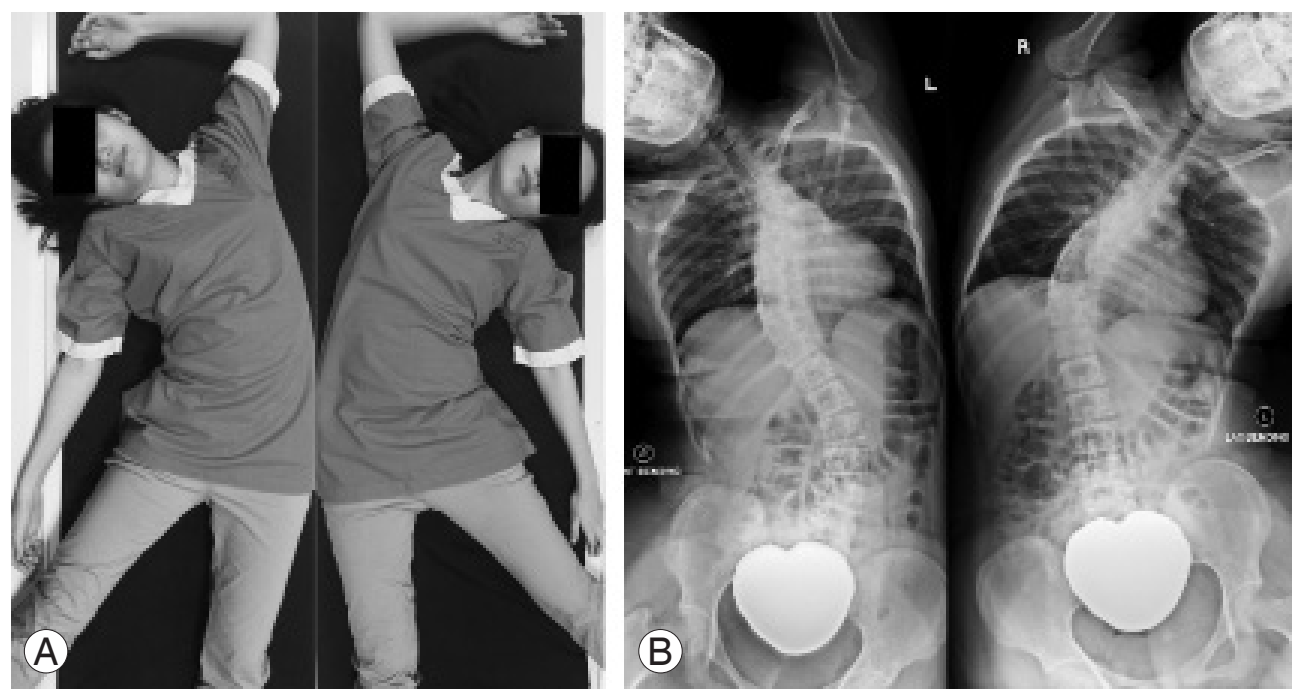

Fig. 1. (A, B) Supervised cervical supine side-bending radiographs. 

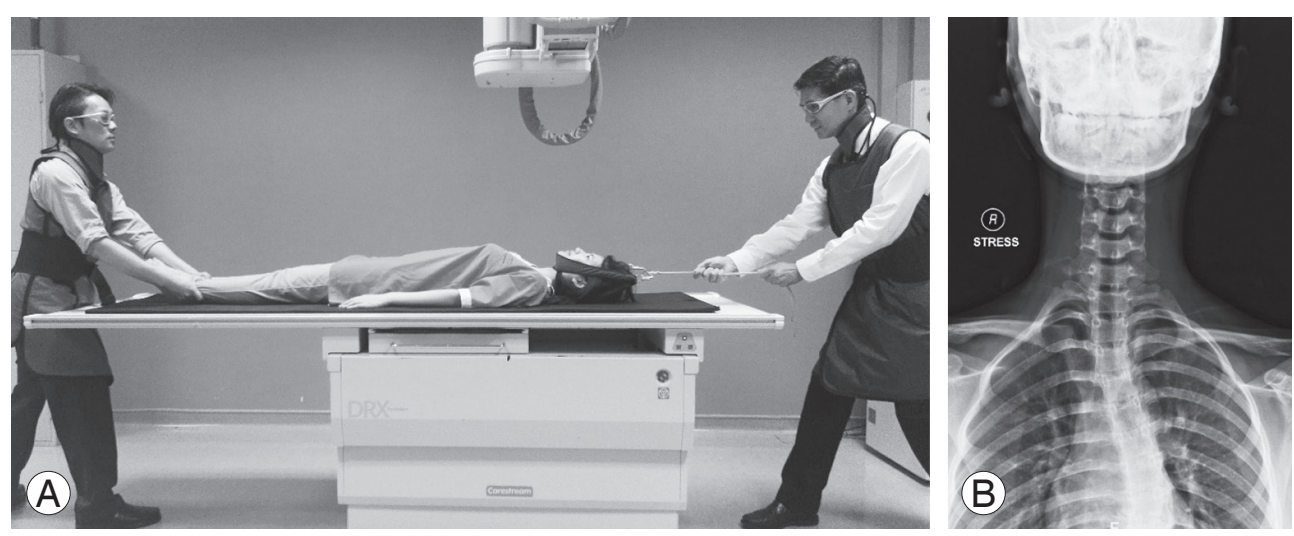

Fig. 2. (A, B) Supervised cervical supine traction radiographs.

raphy, including standing anteroposterior whole spine, standing lateral whole spine, and supine right and left side-bending radiographs. To analyze the flexibility of the PT segments, two physician-supervised radiographs were obtained: (1) CSSB radiograph: a radiograph taken by bending the cervical spine maximally, performed together with bending the whole spine in the supine position. Right and left CSSB radiographs were obtained by bending the cervical spine and the PT segments to the right and left passively while maintaining the head and neck in neutral rotation (Fig. 1). (2) CST radiograph: a PT radiograph taken during traction of the cervical and PT spines with a halter traction device. The traction cranially was counterattracted caudally (Fig. 2).

Patient demographic and radiological parameters included age, gender, weight, height, body mass index, PT angle, MT angle, CSSB PT angle, CST PT angle, and postoperative $\mathrm{PT}$ angle. All measurements were digitally taken using a software (Centricity PACS, ver. 5.0; GE Healthcare, Milwaukee, WI, USA). These parameters were measured in accordance with the "Spinal Deformity Study Group radiographic measurement manual" [17]. For the PT angle measurement, the uppermost vertebra of the MT curve was used as the lowest vertebra of the PT curve, and $\mathrm{T} 1$ or the most tilted vertebra below $\mathrm{T} 1$ was used as the uppermost vertebra of the PT curve.

Definitions and calculations of parameters were as follows: (1) CSSB flexibility (CSSBF $)=(\mathrm{PT}$ angle $-\mathrm{CSSB}$ PT angle $) /(\mathrm{PT}$ angle $) \times 100$; (2) CST flexibility $(\mathrm{CSTF})=(\mathrm{PT}$ angle $-\mathrm{CST} \mathrm{PT}$ angle $) /(\mathrm{PT}$ angle $) \times 100$; (3) correction rate $(\mathrm{CR})=(\mathrm{PT}$ angle - postoperative $\mathrm{PT}$ angle $) /(\mathrm{PT}$ angle $) \times 100$;

(4) CSSB correction index $(\mathrm{CSSBCI})=\mathrm{CR} / \mathrm{CSSBF}$; and (5) CST correction index $(\mathrm{CSTCI})=\mathrm{CR} / \mathrm{CSTF}$.

Explanations of the calculated parameters were as follows. (1) Flexibility: as the value of this parameter increases, it indicates increased flexibility of the PT scoliotic curve. (2) CR: the amount of PT curve correction achieved after surgery. (3) Correction index (CI): a ratio/ index to denote how accurately the flexibility assessment reflects the final surgical correction of the PT scoliotic curve. A value of 1 indicates that the preoperative flexibility assessment is the same as the postoperative CR. A value higher than 1 indicates that the surgical correction is more than the assessed flexibility. A value of less than 1 indicates that the surgical correction is less than the assessed flexibility.

\section{Sample size analysis}

By using one formula for mean of the sample size estimation, CSSB and CST angles were used as outcome variables in this study. Based on the previous study by Kirk et al. [15], the mean for supine side-bending and supine traction Cobb angles of the PT curve were $30.1^{\circ}$ and $24.4^{\circ}$, respectively. The largest sample size was selected among those angles. Thus, the effect size was obtained as 0.47 at $80 \%$ power of the study, indicating that a minimum sample size of 29 subjects was required to detect the differences in Cobb angles. The calculation was performed using $G^{\star}$ Power software (ver. 3.1.9.2; Heinrich-HeineUniversität Düsseldorf, Düsseldorf, Germany; http://www. gpower.hhu.de/) [18].

\section{Statistical analysis}

Data was entered and analyzed using IBM SPSS ver. 23.0 statistical software (IBM Corp., Armonk, NY, USA). Descriptive analysis was performed using One-way analysis 
of variance for quantitative variables and the $\chi^{2}$ test for categorical variables. The strength of correlation was assessed between CSSBF versus CR, CSTF versus CR, CSSB PT angle versus postoperative PT angle, and CST PT angle versus postoperative PT angle for each subgroup and the whole group using Pearson's correlation coefficient. A paired $t$-test was used to determine the differences between CSSBF and CSTF, CSSBCI and CSTCI, and CSSB PT angle and CST PT angle within each group. An a level of 0.05 indicated statistical significance.

\section{Results}

This study recruited 30 patients ( 26 females, four males) with a mean age of $15.3 \pm 3.3$ years. The weight, height, body mass index, PT angle, MT angle, postoperative PT angle, CR, and upper instrumented vertebrae (UIV) are illustrated in Table 1.

The preoperative and postoperative measurements are illustrated in Table 2. Both mean CSSB PT $\left(16.6^{\circ} \pm 10.4^{\circ}\right)$ and CST PT $\left(23.7^{\circ} \pm 10.7^{\circ}\right)$ angles were less than the preoperative standing PT angle $\left(29.4^{\circ} \pm 11.2^{\circ}\right)$ and more than the postoperative PT angle $\left(16.1^{\circ} \pm 7.5^{\circ}\right)$. Most of the UIV were T3. The UIV was generally higher (T2) when there was less flexibility and lower (T4 or T5) when there was greater flexibility.

There were 15 patients (50\%) with a $\mathrm{PT}$ angle $<15^{\circ}$ with CSSB in comparison to five patients (16.7\%) with CST. There were seven patients (23.3\%) with a PT angle of $15^{\circ}-25^{\circ}$ with CSSB in comparison to 12 patients (40.0\%) with CST. There were eight patients $(26.7 \%)$ with a PT angle $>15^{\circ}$ with CSSB in comparison to 13 patients (43.3\%) with CST. There were significant differences between PT angles for CSSB and CST $(p<0.01)$.

The Cobb angle, flexibility, and CI comparisons between the CSSB and CST radiographs are illustrated in Table 3. The CSSB PT angle $\left(16.6^{\circ} \pm 10.4^{\circ}\right)$ was significantly $(p<0.05)$ smaller than the CST PT angle $\left(23.7^{\circ} \pm 10.7^{\circ}\right)$. The CSSBF $(44.2 \% \pm 19.7 \%)$ was significantly $(p<0.05)$ greater than the CSTF $(19.5 \% \pm 18.1 \%)$. The CSSBCI $(1.2 \pm 0.9)$ was significantly $(p<0.05)$ closer to the value 1 in comparison to the CSTCI (4.4 \pm 5.3$)$. There was no significant difference $(p=0.72)$ between the CSSB PT angle $\left(16.6^{\circ} \pm 10.4^{\circ}\right)$ and the postoperative PT angle $\left(16.1^{\circ} \pm 7.5^{\circ}\right)$, but the CST PT angle $\left(23.7^{\circ} \pm 10.7^{\circ}\right)$ was significantly $(p<0.05)$ larger than the postoperative PT angle $\left(16.1^{\circ} \pm 7.5^{\circ}\right)$.

The correlation between the postoperative PT angle and
Table 1. Demographics and radiological parameters

\begin{tabular}{|c|c|}
\hline Characteristic & Value \\
\hline \multicolumn{2}{|l|}{ Demographics } \\
\hline Age (yr) & $15.3 \pm 3.3$ \\
\hline \multicolumn{2}{|l|}{ Gender } \\
\hline Male & 4 \\
\hline Female & 26 \\
\hline Weight (kg) & $44.5 \pm 8.7$ \\
\hline Height (cm) & $156.5 \pm 7.0$ \\
\hline Body mass index $\left(\mathrm{kg} / \mathrm{m}^{2}\right)$ & $18.1 \pm 2.7$ \\
\hline \multicolumn{2}{|l|}{ Radiological parameters } \\
\hline PT angle $\left(^{\circ}\right)$ & $29.4 \pm 11.2$ \\
\hline Main thoracic angle $\left({ }^{\circ}\right)$ & $64.3 \pm 15.5$ \\
\hline Postoperative PT angle $\left(^{\circ}\right)$ & $16.1 \pm 7.5$ \\
\hline Correction rate $(\%)$ & $45.7 \pm 18.1$ \\
\hline \multicolumn{2}{|l|}{ Upper instrumented vertebra } \\
\hline $\mathrm{T} 2$ & 6 \\
\hline T3 & 18 \\
\hline T4 & 5 \\
\hline T5 & 1 \\
\hline
\end{tabular}

Values are presented as mean \pm standard deviation or number. PT, proximal thoracic.

the CSSB PT angle is illustrated in Fig. 3. The correlation between the postoperative PT angle and the CST PT angle is illustrated in Fig. 4. Both the CSSB and CST PT angles are significantly correlated with the postoperative PT angles $(p<0.05)$.

\section{Discussion}

Flexibility assessment of a scoliotic curve in a patient with AIS prior to corrective surgery is important. Several methods of radiographically assessing the flexibility of the main scoliotic curve have been reported [7-14]. Some authors report better assessment of the flexibility of the scoliotic curve with traction under general anesthesia $[19,20]$. However, these reports have only investigated the flexibility of the main scoliotic curve, and none have assessed the flexibility of the PT curve.

The flexibility of the PT curve is an important factor in determining neck and shoulder balance following correction of the MT curve. Neck and shoulder balance following surgery has been studied and reported by many authors. This imbalance can be divided into lateral or 
Table 2. Preoperative and postoperative measurements for each patient

\begin{tabular}{|c|c|c|c|c|c|c|c|c|c|c|}
\hline Patient no. & Lenke & Gender & Age (yr) & $\begin{array}{c}\text { PT } \\
\text { angle }\left({ }^{\circ}\right)\end{array}$ & $\begin{array}{l}\text { CSSB PT } \\
\text { angle }\left({ }^{\circ}\right)\end{array}$ & $\begin{array}{l}\text { CST PT } \\
\text { angle }\left({ }^{\circ}\right)\end{array}$ & $\begin{array}{c}\text { CSSB } \\
\text { flexibility }(\%)\end{array}$ & $\begin{array}{c}\text { CST } \\
\text { flexibility }(\%)\end{array}$ & CSSB CI & CST CI \\
\hline 1 & 1 & F & 12 & 29 & 16 & 26 & 44.8 & 10.3 & 0.8 & 3.3 \\
\hline 2 & 2 & M & 15 & 45 & 38 & 37 & 15.6 & 17.8 & 3.4 & 3.0 \\
\hline 3 & 1 & F & 15 & 22 & 9 & 20 & 59.1 & 9.1 & 0.8 & 5.5 \\
\hline 4 & 1 & M & 21 & 44 & 21 & 41 & 52.3 & 6.8 & 0.9 & 7.0 \\
\hline 5 & 1 & F & 16 & 31 & 13 & 18 & 58.1 & 41.9 & 0.7 & 0.9 \\
\hline 6 & 1 & $\mathrm{~F}$ & 16 & 6 & 4 & 4 & 33.3 & 33.3 & 1.0 & 1.0 \\
\hline 7 & 1 & $\mathrm{~F}$ & 15 & 29 & 7 & 23 & 75.9 & 20.7 & 0.6 & 2.3 \\
\hline 8 & 1 & $\mathrm{~F}$ & 14 & 18 & 5 & 13 & 64.3 & 0.0 & 0.6 & 4.0 \\
\hline 9 & 2 & F & 22 & 37 & 26 & 35 & 29.7 & 5.4 & 0.6 & 3.5 \\
\hline 10 & 1 & $\mathrm{M}$ & 18 & 26 & 13 & 20 & 50.0 & 23.1 & 0.5 & 1.0 \\
\hline 11 & 2 & $\mathrm{~F}$ & 17 & 38 & 32 & 37 & 15.8 & 2.6 & 3.0 & 18.0 \\
\hline 12 & 1 & $F$ & 12 & 22 & 10 & 18 & 54.5 & 18.2 & 0.8 & 2.5 \\
\hline 13 & 1 & $F$ & 16 & 28 & 15 & 21 & 31.8 & 0.0 & 0.6 & 2.0 \\
\hline 14 & 1 & $\mathrm{~F}$ & 16 & 6 & 4 & 1 & 33.3 & 83.3 & 2.0 & 0.8 \\
\hline 15 & 1 & $\mathrm{~F}$ & 14 & 21 & 16 & 20 & 23.8 & 4.8 & 0.2 & 1.0 \\
\hline 16 & 2 & $M$ & 11 & 39 & 25 & 32 & 35.9 & 17.9 & 1.1 & 2.3 \\
\hline 17 & 2 & $\mathrm{~F}$ & 14 & 33 & 26 & 28 & 21.2 & 15.2 & 1.9 & 2.6 \\
\hline 18 & 1 & F & 13 & 30 & 12 & 20 & 60.0 & 33.3 & 0.7 & 1.3 \\
\hline 19 & 1 & $\mathrm{~F}$ & 12 & 15 & 5 & 14 & 66.7 & 6.7 & 1.3 & 13.0 \\
\hline 20 & 1 & $F$ & 12 & 34 & 10 & 27 & 70.6 & 20.6 & 0.6 & 2.1 \\
\hline 21 & 1 & $\mathrm{~F}$ & 14 & 43 & 21 & 27 & 51.2 & 37.2 & 0.6 & 0.8 \\
\hline 22 & 1 & $F$ & 12 & 25 & 16 & 23 & 36.0 & 8.0 & 0.4 & 2.0 \\
\hline 23 & 2 & $\mathrm{~F}$ & 17 & 37 & 30 & 34 & 18.9 & 8.1 & 3.1 & 7.3 \\
\hline 24 & 1 & $\mathrm{~F}$ & 14 & 39 & 4 & 15 & 89.7 & 61.5 & 0.8 & 1.1 \\
\hline 25 & 1 & $F$ & 15 & 24 & 9 & 17 & 62.5 & 29.2 & 0.9 & 1.9 \\
\hline 26 & 1 & $\mathrm{~F}$ & 26 & 16 & 7 & 11 & 41.7 & 0.0 & 1.2 & 7.0 \\
\hline 27 & 2 & $\mathrm{~F}$ & 16 & 47 & 34 & 46 & 27.7 & 2.1 & 1.8 & 24.0 \\
\hline 28 & 1 & $\mathrm{~F}$ & 17 & 18 & 8 & 15 & 55.6 & 16.7 & 1.1 & 3.7 \\
\hline 29 & 2 & $\mathrm{~F}$ & 13 & 44 & 31 & 36 & 29.5 & 18.2 & 2.6 & 4.3 \\
\hline 30 & 2 & $F$ & 13 & 37 & 31 & 32 & 16.2 & 13.5 & 2.7 & 3.2 \\
\hline Mean $\pm S D$ & & & $15.3 \pm 3.3$ & $29.4 \pm 11.2$ & $16.6 \pm 10.4$ & $23.7 \pm 10.7$ & $44.2 \pm 19.7$ & $19.5 \pm 18.1$ & $1.2 \pm 0.9$ & $4.4 \pm 5.3$ \\
\hline
\end{tabular}

PT, proximal thoracic; CSSB, cervical supine side-bending; CST, cervical supine traction; Cl, correction index; F, female; M, male; SD, standard deviation.

Table 3. Cobb angle, flexibility, and correction index for CSSB radiographs and CST radiographs

\begin{tabular}{|c|c|c|c|c|c|c|c|}
\hline Variable & Standing PT & CSSB PT & CST PT & $\begin{array}{c}p \text {-value } \\
\text { (CSSB vs. CST) }\end{array}$ & Postop PT & $\begin{array}{c}p \text {-value } \\
\text { (CSSB vs. postop PT) }\end{array}$ & $\begin{array}{c}p \text {-value } \\
\text { (CST vs. postop PT) }\end{array}$ \\
\hline Cobb angle $\left({ }^{\circ}\right)$ & $29.4 \pm 11.2$ & $16.6 \pm 10.4$ & $23.7 \pm 10.7$ & $<0.001$ & $16.1 \pm 7.5$ & 0.72 & $<0.001$ \\
\hline Flexibility (\%) & - & $44.2 \pm 19.7$ & $19.5 \pm 18.1$ & $<0.001$ & - & - & - \\
\hline Correction index & - & $1.2 \pm 0.9$ & $4.4 \pm 5.3$ & 0.002 & - & - & - \\
\hline
\end{tabular}

Values are presented as mean \pm standard deviation.

CSSB, cervical supine side-bending; CST, cervical supine traction; PT, proximal thoracic; Postop, postoperative. 


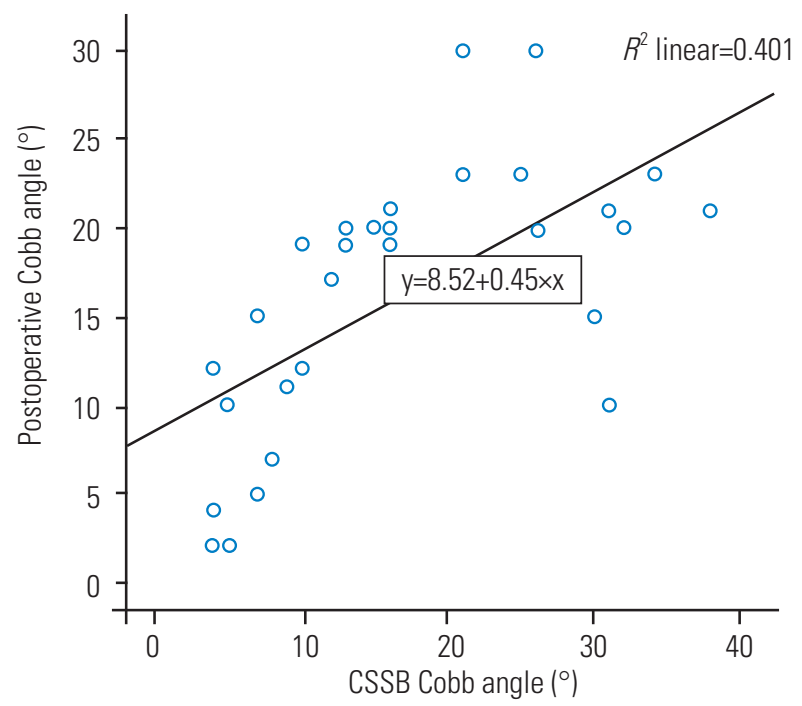

Fig. 3. Significant correlation between postoperative proximal thoracic angle and CSSB proximal thoracic angle $(r=0.63, p<0.001)$. CSSB, cervical supine side-bending.

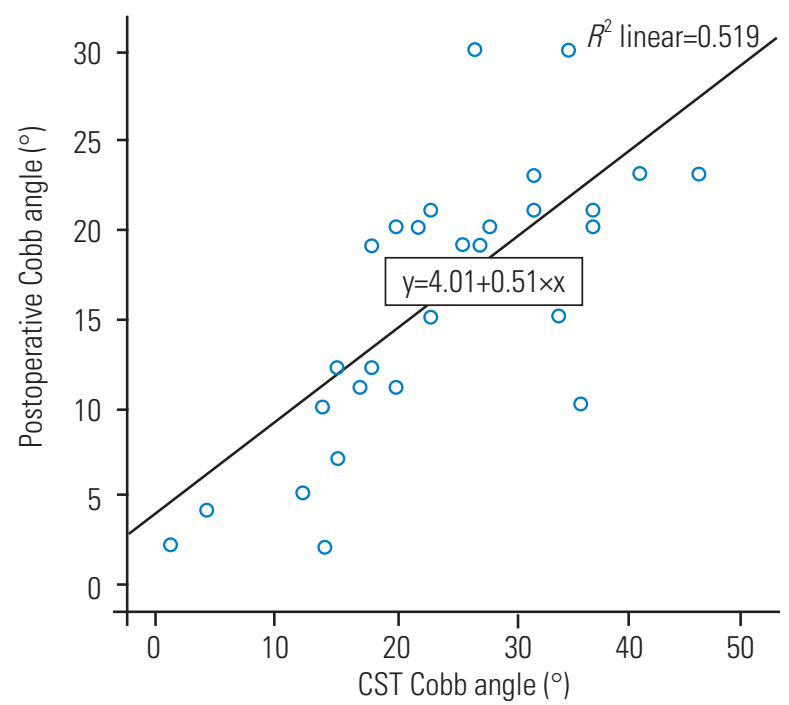

Fig. 4. Significant correlation between postoperative proximal thoracic angle and CST proximal thoracic angle $(r=0.72, p<0.001)$. CST, cervical supine traction.

medial shoulder imbalance [2-4,21-26]. Coracoid height difference, clavicle rib-intersection difference, clavicular angle, and radiological shoulder height contribute to the lateral shoulder imbalance [3,21-25]. T1 tilt, cervical axis, trapezoidal prominence, and neck tilt contribute to the medial shoulder imbalance $[2,4,26]$. The lateral shoulder imbalance can usually be compensated by posture adjustments; however, the medial shoulder imbalance does not respond to posture adjustment and should be resolved during corrective surgery.
To avoid neck and shoulder imbalance, several authors have recommended strategies in their selection of the upper instrumented vertebra. Rose and Lenke [27] recommended fusion to T2 if the left shoulder was higher preoperatively, fusion to T2 or T3 if the shoulder was at level, and fusion to T3 if the right shoulder was higher. Suk et al. [28] recommended that if the PT curve was more than $25^{\circ}$ with a level or elevated left shoulder, it should be treated as a structural curve with fusion up to T1. Elfilky et al. [29] recommended fusion into the PT curve only when it was more than $45^{\circ}$, and a non-fusion strategy was appropriate if the curve was less than $45^{\circ}$. Matsumoto et al. [30] found that the mean postoperative clavicular angle was satisfactory even when a short fusion (UIV at one level below the end vertebra) was used for patients with Lenke 1 AIS.

Kirk et al. [15] compared the ability of supine traction radiography and supine side-bending radiography to assess the flexibility of the PT curve in 15 patients with King V/Lenke 2 AIS. They found that a supine traction radiograph demonstrated greater flexibility of the PT curve than a supine side-bending radiograph. However, with the conventional supine side-bending radiograph, the cervical spine remained neutral and not maximally bent. Thus, it may not reflect the true flexibility of the PT segment.

The CSSB radiograph is an extension of the supine sidebending radiograph. It is concurrently obtained with the supine side-bending radiograph by maximally bending the cervical spine while maximally bending the trunk (Fig. $1)$. In addition, the contralateral arm is cranially placed to the patient's head to allow the shoulder, clavicle, and upper rib cage to further bend the PT segments. A long radiograph film that spans across the cervical spine to the pelvis is taken. In this manner, the flexibility of the upper thoracic segment may be more accurate in the CSSB radiograph in comparison to the conventional supine side-bending radiograph. Chan et al. [16] reported the flexibility of the PT segments of Lenke 1 and 2 curves and how it was able compensate above the potential upper instrumented vertebra by using the CSSB radiograph. For selecting the uppermost instrumented fusion, knowledge of PT flexibility is important to avoid an uncompensated PT curve, which will lead to imbalance of the neck and medial shoulder.

In our study, CSSB was found to have a significantly smaller PT angle $\left(16.6^{\circ} \pm 10.4^{\circ}\right)$ in comparison to CST $\left(23.7^{\circ} \pm 10.7^{\circ}\right)$ (Table 3 ). CSSB had significantly greater flexibility $(44.2 \% \pm 19.7 \%)$ in comparison to CST 
Table 4. Proximal thoracic angles with CSSB radiographs and CST radiographs

\begin{tabular}{lccc} 
Variable & PT angle $<15^{\circ}$ PT angle: $15^{\circ}-25^{\circ}$ & PT angle $>25^{\circ}$ \\
CSSB $^{\text {a) }}$ & $15(50.0)$ & $7(23.3)$ & $8(26.7)$ \\
CST $^{\text {a) }}$ & $5(16.7)$ & $12(40.0)$ & $13(43.3)$ \\
\hline
\end{tabular}

Values are presented as number of patients (\%).

CSSB, cervical supine side-bending; CST, cervical supine traction; PT, proximal thoracic.

${ }^{a}$ Significant difference $(p<0.01)$.

$(19.5 \% \pm 18.1 \%)$. The CSSBCI $(1.2 \pm 0.9)$ was significantly closer to 1 in comparison to the CSTCI $(4.4 \pm 5.3)$. There was no difference between the CSSB PT angle $\left(16.6^{\circ} \pm 10.4^{\circ}\right)$ and the postoperative PT angle $\left(16.1^{\circ} \pm 7.5^{\circ}\right)$. However, the CST PT angle $\left(23.7^{\circ} \pm 10.7^{\circ}\right)$ was significantly larger than the postoperative $\mathrm{PT}$ angle $\left(16.1^{\circ} \pm 7.5^{\circ}\right)$. Therefore, it is concluded that CSSB radiographs demonstrate better flexibility and more accurately predict correctability in comparison to CST radiographs. This may be due to fact that CSSB radiographs are physician supervised, ensuring consistent maximum bending of the cervical spine each time the film is obtained, and CSSB radiographs cause less discomfort for patients as they are obtained by bending the neck passively in comparison to CST radiographs, which are obtained actively by traction, possibly causing resistance from patients.

In addition, when dividing the PT angles into $<15^{\circ}$, $15^{\circ}-25^{\circ}$, and $>25^{\circ}$, there were significant differences between both groups, with more CST radiographs recording PT angles of $15^{\circ}-25^{\circ}$ and $>25^{\circ}$ (Table 4 ). This may affect the selection of UIV fusion levels, as it depends on the PT angle $[16,27]$. A more proximal UIV selection will usually be chosen if the PT angle is stiffer.

There were significant correlations between the CSSB PT angle and the postoperative PT angle and the CST PT angle and the postoperative PT angle (Figs. 3,4 ). Therefore, in terms of correlation, both the CST and the CSSB PT angles correlated with the postoperative PT angle, although CST had a larger PT angle than that of CSSB and the postoperative PT angle.

This study has several limitations. Supervised CSSB radiography requires the physician to be present when the radiograph is obtained to position the patient's neck in maximal lateral bending. A larger sample size will allow subgroup analysis, but it was decided to limit the number of patients who would be exposed to additional radiographs (CST radiograph), which are not routinely ob- tained in our center. The reproducibility of the outcome of each radiograph depends on the patient's cooperation as well as how the radiograph is obtained. Nevertheless, this would be a limitation of most stress radiographs as well.

\section{Conclusions}

We find that the CSSB radiograph is better for demonstrating PT flexibility, and it more accurately predicts correctability in comparison to the CST radiograph. CSSB radiography is a simple additional step that can be added when obtaining conventional supine side-bending radiographs, thereby providing vital and reliable information on the flexibility of the PT segment for patients with Lenke 1 and 2 AIS.

\section{Conflict of Interest}

No potential conflict of interest relevant to this article was reported.

\section{Author Contributions}

Chiu CK, Chan CYW, Kwan MK: conception and design; Chiu CK, Bashir ES, Chan CYW: acquisition and data; Chiu CK, Chiu CK: analysis and interpretation of data; all authors: drafting of the manuscript; Chiu CK, Chan CYW, Kwan MK: critical revision of the manuscript for important intellectual content; Chiu CK: statistical analysis; Kwan MK: obtaining funding; Chan CYW, Kwan MK: administrative, technical or material support; and Chiu CK, Chan CYW, Kwan MK: supervision.

\section{References}

1. Arlet V, Marchesi D, Papin P, Aebi M. Decompensation following scoliosis surgery: treatment by decreasing the correction of the main thoracic curve or "letting the spine go". Eur Spine J 2000;9:156-60.

2. Ono T, Bastrom TP, Newton PO. Defining 2 components of shoulder imbalance: clavicle tilt and trapezial prominence. Spine (Phila Pa 1976) 2012;37:E15116.

3. Matsumoto M, Watanabe K, Kawakami N, et al. Postoperative shoulder imbalance in Lenke Type $1 \mathrm{~A}$ adolescent idiopathic scoliosis and related factors. BMC Musculoskelet Disord 2014;15:366. 
4. Kwan MK, Wong KA, Lee CK, Chan CY. Is neck tilt and shoulder imbalance the same phenomenon?: a prospective analysis of 89 adolescent idiopathic scoliosis patients (Lenke type 1 and 2). Eur Spine J 2016;25:401-8.

5. Smyrnis PN, Sekouris N, Papadopoulos G. Surgical assessment of the proximal thoracic curve in adolescent idiopathic scoliosis. Eur Spine J 2009;18:522-30.

6. Lenke LG, Bridwell KH, O’Brien MF, Baldus C, Blanke K. Recognition and treatment of the proximal thoracic curve in adolescent idiopathic scoliosis treated with Cotrel-Dubousset instrumentation. Spine (Phila Pa 1976) 1994;19:1589-97.

7. Lamarre ME, Parent S, Labelle H, et al. Assessment of spinal flexibility in adolescent idiopathic scoliosis: suspension versus side-bending radiography. Spine (Phila Pa 1976) 2009;34:591-7.

8. Buchler P, de Oliveria ME, Studer D, et al. Axial suspension test to assess pre-operative spinal flexibility in patients with adolescent idiopathic scoliosis. Eur Spine J 2014;23:2619-25.

9. Chen ZQ, Wang CF, Bai YS, et al. Using precisely controlled bidirectional orthopedic forces to assess flexibility in adolescent idiopathic scoliosis: comparisons between push-traction film, supine side bending, suspension, and fulcrum bending film. Spine (Phila Pa 1976) 2011;36:1679-84.

10. Cheung KM, Luk KD. Prediction of correction of scoliosis with use of the fulcrum bending radiograph. J Bone Joint Surg Am 1997;79:1144-50.

11. Takahashi S, Passuti N, Delecrin J. Interpretation and utility of traction radiography in scoliosis surgery: analysis of patients treated with Cotrel-Dubousset instrumentation. Spine (Phila Pa 1976) 1997;22:2542-6.

12. Polly DW Jr, Sturm PF. Traction versus supine side bending: which technique best determines curve flexibility? Spine (Phila Pa 1976) 1998;23:804-8.

13. Hamzaoglu A, Talu U, Tezer M, Mirzanli C, Domanic U, Goksan SB. Assessment of curve flexibility in adolescent idiopathic scoliosis. Spine (Phila Pa 1976) 2005;30:1637-42.

14. Watanabe K, Kawakami N, Nishiwaki Y, et al. Traction versus supine side-bending radiographs in determining flexibility: what factors influence these techniques? Spine (Phila Pa 1976) 2007;32:2604-9.

15. Kirk KL, Kuklo TR, Polly DW Jr. Traction versus side-bending radiographs: is the proximal thoracic curve the stiffer curve in double thoracic curves? Am J Orthop (Belle Mead NJ) 2003;32:284-8.

16. Chan CY, Chiu CK, Kwan MK. Assessing the flexibility of the proximal thoracic segments above the "potential upper instrumented vertebra" using the cervical supine side bending radiographs in Lenke 1 and 2 curves for adolescent idiopathic scoliosis patients. Spine (Phila Pa 1976) 2016;41:E973-80.

17. O’Brien MF, Kuklo TR, Blanke KM, Lenke LG. Spinal deformity study group radiographic measurement manual. Memphis (TN): Medtronic Sofamor Danek; 2008.

18. Faul F, Erdfelder E, Lang AG, Buchner A. G*Power 3: a flexible statistical power analysis program for the social, behavioral, and biomedical sciences. Behav Res Methods 2007;39:175-91.

19. Ibrahim T, Gabbar OA, El-Abed K, Hutchinson MJ, Nelson IW. The value of radiographs obtained during forced traction under general anaesthesia in predicting flexibility in idiopathic scoliosis with Cobb angles exceeding 60 degree. J Bone Joint Surg Br 2008;90:1473-6.

20. Liu RW, Teng AL, Armstrong DG, Poe-Kochert C, Son-Hing JP, Thompson GH. Comparison of supine bending, push-prone, and traction under general anesthesia radiographs in predicting curve flexibility and postoperative correction in adolescent idiopathic scoliosis. Spine (Phila Pa 1976) 2010;35:416-22.

21. Bago J, Carrera L, March B, Villanueva C. Four radiological measures to estimate shoulder balance in scoliosis. J Pediatr Orthop B 1996;5:31-4.

22. Kuklo TR, Lenke LG, Graham EJ, et al. Correlation of radiographic, clinical, and patient assessment of shoulder balance following fusion versus nonfusion of the proximal thoracic curve in adolescent idiopathic scoliosis. Spine (Phila Pa 1976) 2002;27:201320.

23. Akel I, Pekmezci M, Hayran M, et al. Evaluation of shoulder balance in the normal adolescent population and its correlation with radiological parameters. Eur Spine J 2008;17:348-354.

24. Qiu XS, Ma WW, Li WG, et al. Discrepancy between radiographic shoulder balance and cosmetic shoulder balance in adolescent idiopathic scoliosis patients with double thoracic curve. Eur Spine J 2009;18:4551.

25. Yagi M, Takemitsu M, Machida M. Chest cage angle 
difference and rotation of main thoracic curve are independent risk factors of postoperative shoulder imbalance in surgically treated patients with adolescent idiopathic scoliosis. Spine (Phila Pa 1976) 2013;38:E1209-15.

26. Jiang J, Qian BP, Qiu Y, Wang B, Yu Y, Zhu ZZ. Full fusion of proximal thoracic curve helps to prevent postoperative cervical tilt in Lenke type 2 adolescent idiopathic scoliosis patients with right-elevated shoulder. BMC Musculoskelet Disord 2017;18:362.

27. Rose PS, Lenke LG. Classification of operative adolescent idiopathic scoliosis: treatment guidelines. Orthop Clin North Am 2007;38:521-9.
28. Suk SI, Kim WJ, Lee CS, et al. Indications of proximal thoracic curve fusion in thoracic adolescent idiopathic scoliosis: recognition and treatment of double thoracic curve pattern in adolescent idiopathic scoliosis treated with segmental instrumentation. Spine (Phila Pa 1976) 2000;25:2342-9.

29. Elfiky TA, Samartzis D, Cheung WY, Wong YW, Luk $\mathrm{KD}$, Cheung KM. The proximal thoracic curve in adolescent idiopathic scoliosis: surgical strategy and management outcomes. Global Spine J 2011;1:27-36.

30. Matsumoto M, Watanabe K, Ogura Y, et al. Short fusion strategy for Lenke type 1 thoracic curve using pedicle screw fixation. J Spinal Disord Tech 2013;26:93-7. 